\title{
RESILIENT METALLURGICAL SUPPLIER MANAGEMENT - RESEARCH AND PRACTICE GAP
}

\author{
Eva DONOCIKOVÁ, Radim LENORT \\ VSB - Technical University of Ostrava, Faculty of Materials Science and Technology, Ostrava, \\ Czech Republic, EU, radim.lenort@vsb.cz
}

https://doi.org/10.37904/metal.2020.3664

\begin{abstract}
The resilient supplier management is a crucial part of the resilient supply chain management. The topic becomes very urgent due to the increasing number of disruptions, which appears in today's global and turbulent business environment. The paper presents a literature review of the resilient supplier management approaches and practical experiences with their implementation in the metallurgical industry. The aim of the paper is to define the research and practice gap, i.e. identify the state of the art in that field, compare it with practice and propose the directions for further research.
\end{abstract}

Keywords: Supplier management, resilience, metallurgical suppliers

\section{INTRODUCTION}

In today's closely interconnected global economy, traditional management practices that rely on "steady state" conditions are exposed to chaotic external pressures and turbulent changes. The world has experienced several catastrophic events in the recent past, including a global economic collapse, a volcanic eruption in Iceland, an oil spill in the Gulf of Mexico, a catastrophic tsunami, a power outage in Japan, and political upheavals in Africa and the Middle East. Managing the risk of an uncertain future is a challenge that requires resilience - the ability to survive, adapt and grow in the face of turbulent change.

Global supply chains are growing in length as well as complexity and are increasingly experiencing unexpected turbulence [1]. A worldwide survey of multinational enterprises found that at least one major disruption had occurred in $85 \%$ of enterprises in the previous year [2]. Therefore, large companies need approaches and methodologies for crisis management within their complex supply chains. For example, the earthquake and tsunami on March 11 $11^{\text {th }}, 2011$ in Japan and the ensuing nuclear crisis caused an estimated $\$ 195$ billion to $\$$ 305 billion in damages [3]. The loss of $20 \%$ of the national power grid due to decommissioning the nuclear power plant caused Toyota's production to fall by 40,000 vehicles, costing the company $\$ 72$ million a day [4]. Japanese carmakers' stock prices fell to $9.5 \%$ in the first few days, Toyota shares lost more than $17 \%$ of their value over the next month, and total car sales in Japan fell to a 34-year minimal value [5]. The immediate and lasting effects of this natural disaster and the consequent disruption of the supply chain have raised concerns about the resilience of the entire supply chain.

The aim of the paper is to define the research and practice gap, i.e. identify the state of the art in that field, compare it with practice and propose the directions for further research.

\section{RESILIENT SUPPLIER}

Enterprises cannot control volatile and uncertain externalities but can create a system of flexible response for these cases. As individual threats multiply, resilience becomes a key factor. For this reason, enterprises differ in their preparedness for unexpected but fundamental events and shocks. 
The meaning of the English noun "resilience" is the basis for the definition of a resilient supplier. The Oxford Dictionary lists two basic meanings of the word:

- the ability of a substance or object to return to its original state after a change = flexibility,

- $\quad$ the ability to recover quickly from problems = toughness.

Some scientists have defined resilience as the ability of a system to recover from disruption [6,7]. Maklan and Jüttner [8] argue that risk management and knowledge management have an impact on resilience. Haimes [9] suggested that the definition of resilience should refer to the ability to withstand disruption and recovery within a reasonable time and cost. Holcomb and Ponomarov [10] suggested that logistical capacity is related to resilience. Coordination and integration skills can improve the ability to face disruptions. The definition of resilience with regard to Allenby and Fink [11] and Pregenzer [12] emphasises the system's ability to maintain its function in the event of a disaster. Based on a systematic literature search, Hosseini et al. [13] identified four areas of resilient enterprise:

- $\quad$ organisational area,

- social area,

- $\quad$ economic area,

- technological area.

Papadopoulos et al. [14] emphasised the role of rapid confidence-building, public-private partnerships and the quality of information sharing in promoting supply chain resilience.

\section{RESILIENT SUPPLIER MANAGEMENT APPROACHES}

Supplier management is an important issue in a resilient supply chain and day-to-day business operations. It is considered to be one of the strategic activities of enterprises [15] and a difficult and complex process [16]. In the 1990s, scientists began studying supplier management from new perspectives. They focused on the selection of sustainable and resilient suppliers, and therefore, the criteria considered in the standard selection process changed accordingly. However, researchers have not come to an agreement on the criteria for selecting resilient suppliers. Vugrin et al. [17] defines resilience from the perspective of disruption prevention and post-termination recovery and believes that resilience includes absorption, adaptive and regenerative capabilities. Baek et al. [18] argued that flexibility is the driving force behind a resilient supply chain, while Tamvakis et al. [19] emphasises the role of transport. Rajesh and Ravi [20] considered that the key factors to consider when choosing resilient suppliers were: vulnerability, cooperation, risk awareness and supply chain continuity management.

A very interesting article published in the Harvard Business Review [21] shows the following:

- Today's management toolkit is dominated by financial performance management. As a result, very few companies are able to explicitly design, measure and manage resilience.

- Companies and shareholders often focus on maximising short-term returns. In contrast, resilience requires a multi-level perspective: giving up a certain amount of revenue or performance today for more sustainable performance in the future.

- Companies mainly focus on creating and implementing stable plans, which works well when causal relationships are clear, predictable, and unchanging. Resilience deals with what is unknown, variable, unpredictable and unlikely - and therefore has significant consequences.

- In the current corporate capitalism model, every company is considered an economic island that requires individual optimisation. While this simplifies governance and accountability, it masks the extent of economic and social interdependence between the various stakeholders. In contrast, resilience is a feature of systems: the resilience of individual companies does not mean much if their supply base, customer base or the social systems which they depend on are disrupted. 
For this reason, resilience management requires more than just grafting new ideas or tools onto today's approaches. It requires a fundamentally different mental business model - a model that includes complexity, uncertainty, interdependence, system thinking and a multi-level perspective.

Of course, many companies already implement some form of risk management - but mostly to understand and minimise exposure to specific known risks. Approaches to increase the resilience of suppliers to known risks include in particular:

- $\quad$ Business Continuity Planning (BCP),

- $\quad$ Failure Mode and Effects Analysis (FMEA),

- $\quad$ a set of ISO standards, particularly ISO 9001, ISO 14001, ISO 45001, ISO 13485,

- $\quad$ IATF Standard 16949,

- Hazard Analysis and Critical Control Points (HACCP),

- $\quad$ a set of VDA standards.

Resilience must also deal with unidentified risks and must take the adaptations and transformations into account that company must make in order to absorb the business environment burden and even turn it to an advantage. The situation is much more complicated in this area. Currently, there are not many approaches that address this issue. The closest to detecting unpredictable risks is BCP and FMEA.

\section{PRACTICE FROM THE METALLURGICAL SUPPLIERS' PERSPECTIVE}

From the information above it is clear that in order for supply chains to increase their resilience, they need to address:

- $\quad$ working with generally known risks and implementing existing approaches,

- $\quad$ rapid implementation of measures responding to newly identified risks and disruptions - as soon as unpredictable complications occur, the risk is no longer unknown and everything needs to be well analysed and, if required, the necessary measures implemented,

- $\quad$ even risks with significant impacts that are not particularly predictable.

The experience of the article's authors from working with metallurgical suppliers has shown that many activities are only implemented in part. The results of a number of supplier audits revealed failures in the basic principles of operation of general approaches. For example, suppliers claim that quality is their number one priority, that they have a system of continuous improvement in place, but unfortunately the reality does not correspond to this. This is not just about ignoring established systems or inconsistencies and human error. One of the main reasons is the disproportionate pressure to minimise costs. Therefore, suppliers employ less experienced workers in order to reduce labour costs as much as possible. This is not the only problem. In an effort to reduce costs or to achieve promised deadlines, suppliers also reduce quality costs associated with, for example, continuous independent quality verification (audits or even measurements). These are only considered approaches that are to strengthen the suppliers' resilience based on solutions to known risks.

Another problem is the excessive sophistication of some approaches and the pressure to implement them. Large companies, especially in the automotive industry, are pushing their suppliers to implement wide-ranging approaches that often overwhelm suppliers unnecessarily. For large companies, there are large departments that have the necessary capacity and experience to solve the activities. However, the situation is different for medium and smaller companies, which are deeper in the supply chain. Furthermore, unfortunately, it is often the case that no one deals with the added value of these measures. Last but not least, there is the problem that in an effort to please their management, company managers implement measures that the company does not need at all. This is often the case with managers who come from the automotive industry and are used to certain standards. However, they do not realise that in the metallurgical industry given approaches are not required. 
Unfortunately, from practical experience there is only a very small percentage of suppliers in the metallurgical industry that have implemented a BCP. Once businesses have implemented it, they usually only address common risks such as fire.

\section{RESEARCH AND PRACTICE GAP}

Based on the authors' literature search and practical experience, the following fundamental research and practical gaps can be identified in the field of resistance management of metallurgical suppliers:

- $\quad$ There is a lack of consistency in implementing basic measures that lead to eliminating commonly known risks and strengthening suppliers' resilience.

- There is no simple methodology that would work with individual suppliers and try to continuously improve their resilience. Instead, overly sophisticated solutions are applied for which suppliers either do not have the necessary capacity or knowledge.

- $\quad$ Closely related to the previous point is the fact that the added value of individual measures is not evaluated.

- $\quad$ Mutually advantageous supplier-customer relationships are not observed. There is disproportionate pressure on suppliers, which ultimately does not bring the necessary results.

- $\quad$ There are not many approaches on how to manage a supplier's resilience to unpredictable risks.

- Suppliers' resistance to unforeseeable risks is not addressed in an appropriate way.

\section{CONCLUSION}

The defined research and practical gap clearly indicate the need to find new approaches to managing supplier resilience within the metallurgical industry. Therefore, the authors' further research will focus on the development of a methodology for managing the supplier resilience, mainly focusing on medium-sized metallurgical suppliers. The methodology will include a series of activities that need to be implemented with the supplier in order to increase its resilience. The methodology will include a description of:

- what requirements will be placed on the experience of the staff who have to deal with the given activities at the supplier and in the company itself,

- how to proceed regularly and consistently when implementing the given activities,

- how to regularly evaluate the obtained data and how to work with them further (both at the supplier and at the company's own industrial enterprise),

- how to regularly monitor and evaluate the added value of implemented activities.

\section{ACKNOWLEDGEMENTS}

The work was supported by the specific university research of Ministry of Education, Youth and Sports of the Czech Republic at VSB - Technical University of Ostrava No. SP2020/61.

\section{REFERENCES}

[1] BLACKHURST, J., CRAIGHEAD, C.W., ELKINS, D., HANDFIELD, R.B. An empirically derived agenda of critical research issues for managing supply-chain disruptions. International Journal of Production Research. 2005, vol. 43, no. 19 , pp. 4067-4081.

[2] BUSINESS CONTINUITY INSTITUTE. Supply Chain Resilience. 3rd Annual Survey [online]. 2011. [viewed 202005-17]. Available from: http://www.bcipartnership.com/supplychainform.html.

[3] NANTO, D.K., COOPER, W.H., DONNELLY, J.M., JOHNSON, R. Japan's 2011 Earthquake and Tsunami: Economic Effects and Implications for the United States [online]. Congressional Research Service, 2011 [viewed 2020-05-17]. Available from: https://fas.org/sgp/crs/row/R41702.pdf. 
[4] TAKAHASHI, Y., KACHI, H. Plant Closures Imperil Global Supplies. The Wall Street Journal [online]. 2011 [viewed 2020-05-17]. Available from: https://www.wsj.com/articles/SB10001424052748704027504576198961775199034.

[5] TAKAHASHI, Y. Japan Auto Demand to Fall on Earthquake Woes. The Wall Street Journal [online]. 2011 [viewed 2020-05-17]. Available from: https://www.wsj.com/articles/SB10001424052970204422404576596174036911558.

[6] MITROFF, I.I., ALPASLAN, M.C. Preparing for evil. Harvard Business Review [online]. Harvard Business Review Publishing, 2003 [viewed 2020-05-17]. Available from: https://hbr.org/2003/04/preparing-for-evil.

[7] CHRISTOPHER, M., PECK, H. Building the resilient supply chain. The International Journal of Logistics Management. 2004, vol. 15, no. 2, pp. 1-13.

[8] MAKLAN, S., JÜTTNER, U. Supply chain resilience in the global financial crisis: An empirical study. Supply Chain Management. 2011, vol. 16, no. 4, pp. 246-259.

[9] HAIMES, Y.Y. On the definition of resilient systems. The International Journal of Logistics Management. 2009, vol. 29, no. 4, pp. 498-501.

[10] HOLCOMB, M.C., PONOMAROV, S.Y. Understanding the concept of supply chain resilience. The International Journal of Logistics Management [online]. 2009, vol. 20, no. 1, pp. 124-143.

[11] ALLENBY, B., FINK, J.H. Toward inherently secure and resilient societies. Science. 2005, vol. 309, no. 5737, pp. 1034-1036.

[12] PREGENZER, A.L. Systems Resilience: A New Analytical Framework for Nuclear Nonproliferation [online]. California, USA: Sandia National Laboratories, 2011.

[13] HOSSEINI, S., BARKER, K., RAMIREZ-MARQUES, J.E. A review of definitions and measures of system resilience. Reliability Engineering \& System Safety. 2016, vol. 145, pp. 47-61.

[14] PAPAdOPOUlOS, T., GUNASEKARAN, A., DUBEY, R., ALTAY, N., FROSSO-WAMBA, S. The role of Big Data in explaining disaster resilience in supply chains for sustainability. Journal of Cleaner Production. 2017, vol. 142, no. 2, pp. 1108-1118.

[15] KUMAR, R., PADHI, S.S., SARKAR, A. Supplier selection of an Indian heavy locomotive manufacturer: An integrated approach using Taguchi loss function, TOPSIS, and AHP. IIMB Management Review. 2019, vol. 31, no. 1 , pp. 78-90.

[16] BÜYÜKÖZKAN, G., GÜLERYÜZ, S. A new integrated intuitionistic fuzzy group decision making approach for product development partner selection. Computers \& Industrial Engineering. 2016, vol. 102, pp. 383-395.

[17] VUGRIN, E.D., WARREN, D.E., EHLEN, M.A. A resilience assessment framework for infrastructure and economic systems: Quantitative and qualitative resilience analysis of petrochemical supply chains to a hurricane. Process Safety Progress. 2011, vol. 30, no. 3, pp. 280-290.

[18] BAEK, J.S., MERONI, A., MANZINI, E. A socio-technical approach to design for community resilience: A framework for analysis and design goal forming. Design Studies. 2015, vol. 40, pp. 60-84.

[19] TAMVAKIS, P., XENIDIS, Y. Resilience in transportation systems. Procedia - Social and Behavioral Sciences. 2012, vol. 48, pp. 3441-3450.

[20] RAJESH, R., RAVI, V. Supplier selection in resilient supply chains: a grey relational analysis approach. Journal of Cleaner Production. 2015, vol. 86, no. 15, pp. 343-359.

[21] REEVES, M., WHITAKER, K. A Guide to building a more resilient business. Harvard Business Review [online]. Harvard Business School Publishing, 2020 [viewed 2020-05-17]. Available from: https://hbr.org/2020/07/a-guideto-building-a-more-resilient-business. 